\title{
A randomized split mouth study for comparison of clinical success rate of GIOMER based sealant and conventional fluoride releasing pit and fissure sealant in first permanent molars
}

\author{
Sameer Sharma ${ }^{1}$, Radhika Chopra ${ }^{2}$, Pulkit Jhingan ${ }^{3 *}$, Vinod Sachdev ${ }^{4}$ \\ ${ }^{1}$ Former PG Student, ${ }^{2}$ Professor, ${ }^{3}$ Senior Lecturer, ${ }^{4}$ Professor \& Head, Dept. of Pedodontics and Preventive Dentistry, Professor, I.T.S- \\ Centre for Dental Studies \& Research Muradnagar, Ghaziabad, Uttar Pradesh, India
}

*Corresponding Author: Pulkit Jhingan

Email: dr.pulkitjhingan@its.edu.in

\begin{abstract}
Objective: To compare and assess the application time, retention, marginal staining, development of carious lesion and plaque accumulation of GIOMER based pit and fissure sealants with conventional fluoride releasing pit and fissure sealant in first permanent molars.

Study Design: Fifty children in the age range of 6-9 years, following acceptable home dental care, had participated in the study. A randomized split-mouth design was used in which two fissure sealants (Helioseal $\mathrm{F}$ and Beautisealant) were randomly placed in 50 harmonizing contralateral duo of permanent first molars. Sealants were gauged by a single skilled and calibrated examiner using mouth mirrors and probes following the USPHS criteria at 3-, 6- and 12-months follow up.

Results: Mean application time for Beautisealant was significantly less i.e. 155.39 seconds than that of Helioseal $\mathrm{F}$ i.e. 260.91 seconds. The retention rates at 3, 6 and 12 months for Helioseal $\mathrm{F}$ was $80.4 \%, 76.1 \%$ and $60.9 \%$ and for Beautisealant was $71.7 \%, 65.2 \%$ and $47.8 \%$ respectively.

Conclusion: Application time of Beautisealant was significantly less than Helioseal F, but Helioseal F demonstrates better retention rate, while both material displayed similarresults for marginal staining, development of carious lesion and plaque accumulation.
\end{abstract}

Keywords: Pit and fissure sealants, Retention, Giomer.

\section{Introduction}

Dental caries is an infectious disease of the tooth caused by the micro-organisms attacking the susceptible host tooth in collaboration with substrate that results in confined dissolution and ruination of calcified tissue with time. Pit and fissures of first permanent molars, due to its extended eruption phase have highest prevalence of dental caries as they provide excellent instinctive shelter for the growth of microbes. Preventive measures such as control of bacterial plaque and topical fluoride application have its effect on such surfaces but sealing the pits and fissures just after tooth eruption may be one of the most important method in providing resistance to caries. ${ }^{1}$

Dental sealants form a smooth layer avoiding sticking of food and thus providing hindrance to bacterial survival in pits and fissures. ${ }^{2,3}$

Resin-based fluoride releasing conventional sealants are preferred choice, however use of phosphoric acid demineralizes the enamel layer and have elongated treatment time and is more technique sensitive. ${ }^{4}$

Newer GIOMER based pit and fissure sealant using self-etch primer eliminatesphosphoric acid etch and rinse, self-etch adhesive combine etching, priming and bonding into single step, thus conserving the enamel and reducing chair side time especially in uncooperative children. However, retention of self-etch adhesive as compared to conventional sealants is questionable. ${ }^{5}$

Hence, a study was conducted to evaluate the clinical performance of GIOMER based sealant (Shofu Beautisealant) in comparison to conventional fluoride releasing pit and fissure sealant (Vivadent Ivoclar Helioseal F) in first permanent molars.

\section{Material and Methods}

Fifty children in the age of six to nine years were selected from the Out-patient Department of Pedodontics and Preventive Dentistry, I.T.S Centre for Dental Studies and Research, Muradnagar.

Study was approved by the ethical committee of the institution. Consent form was signed by each patient's parents/guardians before enrolling them in the study.

Sample size was evaluated using the formula: $N=2\left(Z_{\alpha}+Z_{\beta}\right)^{2} /(d)^{2}$ where, $\alpha=$ First type of error; $\beta=$ Second type of error; $d=$ Allowable difference.

A split-mouth design was used in which the two fissure sealants (Helioseal F and Beautisealant) were randomly placed in fifty harmonizing contralateral duo of permanent first molars. Group 1 (Helioseal F) and Group 2 (Beautiselant)

Software (Stat Trek random number generator) based random numbers were generated to randomly allocate the sealants for placement on either side of the arch in all the patients. ${ }^{6}$ Both teeth were sealed during the same appointment starting with the right side and followed by the left side.

Children included in the study were having both left and right first permanent molars indicated for sealant application from either arch. Teeth with no sign of occlusal caries and patient following acceptable home dental care measures. 
Uncooperative patient and unerupted/ partially erupted teeth on the contralateral side and patients having any chronic medical diseases or receiving long term medication were excluded.

\section{Procedure}

The tooth was cleaned with wet bristle brush at low speed and then rinsed and dried. Isolation was carried out using cotton rolls and assisted suctioning to maintain a dry operating field.

Helioseal F sealant (Group 1): $37 \%$ phosphoric acid etchant was applied on the occlusal surface directly with the syringe for 30 seconds. A white frosted appearance on the enamel confirmed adequate etching. Helioseal $\mathrm{F}$ sealant was then applied to the pits and fissures according to the manufacturer's instructions. The sealantwas cured for 20 seconds using LED light curing unit. Occlusion was checked using articulating paper and extra material was reduced with slow speed finishing burs.

Beautisealant (Group 2): Adequate amount of primer was first dispensed onto V-DISH, which was available in the company kit after following the same procedure as above for cleaning and drying the teeth. A fine micro-brush was used to apply the primer on the enamel surface of pits and fissures. It was left undisturbed for at least 10 seconds, followed by gentle air drying to avoid dispersion of primer.

The sealant was then applied directly from the syringe into the pit and fissures slowly and steadily and light cured for 20 seconds as per manufacturer's instructions. Occlusion was checked and reduced as per the patient comfort.

\section{Clinical evaluation}

\section{a) Application time}

Time in seconds for each sealant application was recorded by the operator, using the digital stopwatch, beginning from the placement of first cotton roll for isolation till the end of the curing cycle.

b) Retention, marginal staining and development of carious lesion

All the margins were inspected and explored to check for any marginal discoloration and seal. Patients were then recalled at 3-, 6- and 12- month intervals to check for retention, marginal Staining and development of carious lesion according to the Modified United States Public Health Services (USPHS) criteria. ${ }^{7}$

\section{c) Plaque disclosing procedure}

Two toned plaque disclosing agent was used to check for plaque accumulation. The agent was applied on sealed dried tooth for 60 seconds and rinsed once with water. Blue color displayed accumulation of plaque. Absence and presence of plaque was recorded on follow up at each interval accordingly.

\section{d) Blinding}

Follow up examination for pit and fissure sealant was done by trained and calibrated evaluator, specialists in pediatric dentistry. The operator could not be blinded for application of materials and recording the time for application because different type of procedures were required for both the materials according to the manufacturer's instructions. The evaluator was blinded regarding all the clinical recordings to be scored for the two sealant materials.

\section{Statistical analysis}

The data was compiled and analyzed using SPSS version 20. Student t-test was used to compare the application time. Pearson Chi-Square test was used to compare the other parameters of clinical evaluation.

\section{Results}

In the present in vivo study, fifty children with mean age 7.8 \pm 1.13 . The sealants were evaluated for the clinical performance including retention, marginal staining, development of carious lesion and plaque accumulation at 3 , 6 and 12 month intervals.

$56 \%$ samples were male i.e. $\mathrm{n}=28$ as compared to $46 \%$ females i.e. $\mathrm{n}=22$.

Two patients were dropped out from the study as they did not turn up for recalls. 92 teeth were evaluated for the study.

Application time at zero day was compared using Student t-test. Mean time for Group 1 (Helioseal F) was $260.91 \pm 58.52$ seconds and Group 2 (Beautisealant) was $155.39 \pm 46.62$ seconds. Results showed that mean time of application for group 2 was significantly lower than that of group 1. $(P=0.0001)$. (Table 1$)$

Overall retention of sealants at each recall is shown in Table 2, 3, 4. The frequency of retention of a sealant fell gradually from $76.05 \%$ after 3 months to $54.35 \%$ after 12 months. The total loss of Beautisealant $(26.1 \%, 30.4 \%$ and $41.3 \%$ at 3,6 and 12 months, respectively) was significantly more than the total loss of Helioseal F $(8.7 \%, 10.9 \%, 13 \%$, respectively). $(p=0.032,0.036,0.006)$.

Graph 1 shows marginal staining at 3,6 and 12 months was absent in $97.6 \%, 90.2 \%$ and $87.5 \%$ in group 1 and $97.1 \%, 93.8 \%$ and $92.6 \%$ in group 2 , respectively $(p=$ $0.879,0.588,0.504$ ).

There was no development of carious lesion at 3 and 6 months. Only 1 tooth in each group showed development of carious lesion at 12 months (Table 5). $(p=1.000)$.

Plaque accumulation was present in $2.4 \%, 2.4 \%$ and $2.5 \%$ in group 1 and $8.6 \%, 6.1 \%$ and $14.3 \%$ in group 2 at 3, 6 and 12 months (Table 6). There was no statistical difference between two groups $(p=0.223,0.432$ and 0.067). 


\section{Graph 1}

\section{Marginal staining}

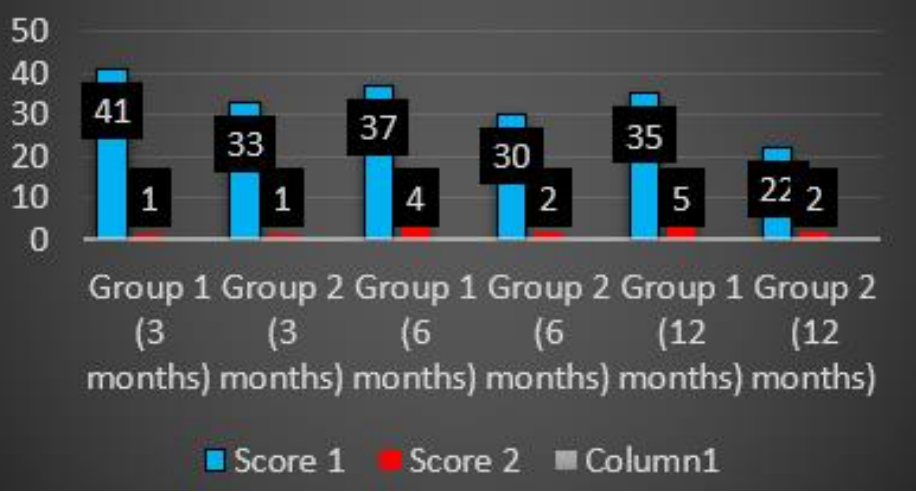

Table 1: Comparison of time calculated for application at zero day in both groups

\begin{tabular}{|l|c|c|c|c|c|}
\hline & Group & $\mathbf{N}$ & Mean (seconds) & Std. Deviation & $\boldsymbol{P}$ value \\
\hline \multirow{2}{*}{ Time } & 1 & 46 & 260.91 & 58.520 & $0.0001^{* *}$ \\
\cline { 2 - 6 } & 2 & 46 & 155.39 & 46.620 & \\
\hline
\end{tabular}

NS $=$ not significant, ${ }^{*}$ significant $=\mathrm{P}<0.05,{ }^{* * *}$ highly significant $=\mathrm{P}<0.01$

Table 2: Comparison of retention at 3 months in both groups

\begin{tabular}{|c|c|c|c|c|c|c|}
\hline & & \multicolumn{3}{|c|}{ Retention at 3 months } & \multirow[t]{2}{*}{ Total } & \multirow[t]{2}{*}{$P$ Value } \\
\hline & & $\begin{array}{l}\text { Score 1 } \\
\mathbf{N}(\%)\end{array}$ & $\begin{array}{c}\text { Score 2 } \\
\mathbf{N}(\%)\end{array}$ & $\begin{array}{c}\text { Score 3 } \\
\mathbf{N}(\%)\end{array}$ & & \\
\hline \multirow[t]{2}{*}{ Group } & \multirow[t]{2}{*}{1} & 37 & 5 & 4 & 46 & \multirow{3}{*}{$0.032^{*}$} \\
\hline & & $(80.4 \%)$ & $(10.9 \%)$ & $(8.7 \%)$ & $100.0 \%$ & \\
\hline \multirow[t]{2}{*}{ Group } & \multirow[t]{2}{*}{2} & 33 & 1 & 12 & 46 & \\
\hline & & $(71.7 \%)$ & $(2.2 \%)$ & $(26.1 \%)$ & $100.0 \%$ & \\
\hline
\end{tabular}

${ }^{\mathrm{NS}}=$ not significant, ${ }^{*}$ significant $=\mathrm{P}<0.05,{ }^{* *}$ highly significant $=\mathrm{P}<0.01$

Table 3: Comparison of retention at 6 months in both groups

\begin{tabular}{|c|c|c|c|c|c|c|}
\hline & & \multicolumn{3}{|c|}{ Retention at 6 months } & \multirow[t]{2}{*}{ Total } & \multirow[t]{2}{*}{$P$ Value } \\
\hline & & $\begin{array}{c}\text { Score } 1 \\
\mathbf{N}(\%)\end{array}$ & $\begin{array}{c}\text { Score } 2 \\
\mathbf{N}(\%)\end{array}$ & $\begin{array}{c}\text { Score } 3 \\
\mathbf{N}(\%)\end{array}$ & & \\
\hline \multirow[t]{2}{*}{ Group } & \multirow[t]{2}{*}{1} & 35 & 6 & 5 & 46 & \multirow{3}{*}{$0.036^{*}$} \\
\hline & & $(76.1 \%)$ & $(13.0 \%)$ & $(10.9 \%)$ & $100.0 \%$ & \\
\hline \multirow[t]{2}{*}{ Group } & \multirow[t]{2}{*}{2} & 30 & 2 & 14 & 46 & \\
\hline & & $(65.2 \%)$ & $(4.3 \%)$ & $(30.4 \%)$ & $100.0 \%$ & \\
\hline
\end{tabular}

${ }^{\mathrm{NS}}=$ not significant, ${ }^{*}$ significant $=\mathrm{P}<0.05,{ }^{* *}$ highly significant $=\mathrm{P}<0.01$

Table 4: Comparison of retention at 12 months in both groups

\begin{tabular}{|c|c|c|c|c|c|c|}
\hline-3 & & \multicolumn{3}{|c|}{ Retention at 12 months } & \multirow[t]{2}{*}{ Total } & \multirow[t]{2}{*}{$P$ Value } \\
\hline & & $\begin{array}{c}\text { Score 1 } \\
\mathbf{N}(\%)\end{array}$ & $\begin{array}{c}\text { Score 2 } \\
N(\%)\end{array}$ & $\begin{array}{c}\text { Score } 3 \\
\mathbf{N}(\%)\end{array}$ & & \\
\hline \multirow[t]{2}{*}{ Group } & \multirow[t]{2}{*}{1} & 28 & 12 & 6 & 46 & \\
\hline & & $(60.9 \%)$ & $(26.1 \%)$ & $(13.0 \%)$ & $100.0 \%$ & \multirow{2}{*}{$0.006^{* *}$} \\
\hline \multirow[t]{2}{*}{ Group } & \multirow[t]{2}{*}{2} & 22 & 5 & 19 & 46 & \\
\hline & & $(47.8 \%)$ & $(10.9 \%)$ & $(41.3 \%)$ & $100.0 \%$ & \\
\hline
\end{tabular}

${ }^{\mathrm{NS}}=$ not significant, ${ }^{*}$ significant $=\mathrm{P}<0.05,{ }^{* *}$ highly significant $=\mathrm{P}<0.01$ 
Table 5: Comparison of development of carious lesion at 12 months in both groups

\begin{tabular}{|c|c|c|c|c|c|}
\hline & & \multicolumn{2}{|c|}{ Development of Carious Lesion at 12 months } & \multirow[t]{2}{*}{ Total } & \multirow[t]{2}{*}{$P$ Value } \\
\hline & & $\begin{array}{c}\text { Score 1 } \\
\mathbf{N}(\%) \\
\end{array}$ & $\begin{array}{c}\text { Score 2 } \\
\mathbf{N}(\%) \\
\end{array}$ & & \\
\hline \multirow[t]{2}{*}{ Group } & \multirow[t]{2}{*}{1} & 1 & 45 & 46 & \\
\hline & & $(2.2 \%)$ & $(97.8 \%)$ & $100.0 \%$ & \multirow{2}{*}{$1.000^{\mathrm{NS}}$} \\
\hline \multirow[t]{2}{*}{ Group } & \multirow[t]{2}{*}{2} & 1 & 45 & 46 & \\
\hline & & $(2.2 \%)$ & $(97.8 \%)$ & $100.0 \%$ & \\
\hline
\end{tabular}

${ }^{\mathrm{NS}}=$ not significant, ${ }^{*}$ significant $=\mathrm{P}<0.05,{ }^{* *}$ highly significant $=\mathrm{P}<0.01$

Table 6: Comparison of plaque accumulation at 12 months in both groups

\begin{tabular}{|c|c|c|c|c|c|}
\hline 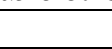 & & \multicolumn{2}{|c|}{ Plaque Accumulation at 12 months } & \multirow[t]{2}{*}{ Total } & \multirow[t]{2}{*}{$P$ Value } \\
\hline & & $\begin{array}{c}\text { Score 1 } \\
\mathbf{N}(\%)\end{array}$ & $\begin{array}{c}\text { Score 2 } \\
\mathbf{N}(\%)\end{array}$ & & \\
\hline \multirow{2}{*}{ Group } & \multirow[t]{2}{*}{1} & 1 & 39 & 40 & \multirow{3}{*}{$0.067^{\mathrm{NS}}$} \\
\hline & & $(2.5 \%)$ & $(97.5 \%)$ & $100.0 \%$ & \\
\hline \multirow[t]{2}{*}{ Group } & \multirow[t]{2}{*}{2} & 4 & 24 & 28 & \\
\hline & & $(14.3 \%)$ & $(85.7 \%)$ & $100.0 \%$ & \\
\hline
\end{tabular}

NS $=$ not significant, ${ }^{*}$ significant $=\mathrm{P}<0.05,{ }^{* *}$ highly significant $=\mathrm{P}<0.01$

\section{Discussion}

Dental caries is one of the most prevalent and important dental problem affecting most of the children in India. ${ }^{8}$ Dietary patterns which include more of carbohydrates and sugars are the predominant cause for the high prevalence of dental caries which affect the newly erupted first permanent molars. ${ }^{9}$ Caries occurrence in the pits and fissures of the occlusal surface of the molars is responsible for about $67-$ $90 \%$ of caries in children within age of 5 to 17 years. ${ }^{10}$ Karunakaran $\mathrm{R}$ et al., conducted a study to evaluate the prevalence of dental caries among school going children in sub-urban area of south India and reported an overall prevalence of $65.9 \% .{ }^{11}$ Dental sealants (also termed pit and fissure sealants, or simply fissure sealants)form an important part of School Dental Health Programs conducted by various Dental Institutes in India. ${ }^{12}$

Helioseal F is a conventional phosphoric acid etch and rinse light-curing, white-shaded fissure sealant featuring fluoride release. Fluoride is known to increase enamel resistance via the promotion of remineralization and inhibition of demineralization; reduce plaque growth and plaque activity; have a bacteriotoxic effect. ${ }^{13} \mathrm{Clinical}$ studies for Helioseal $\mathrm{F}$ have shown to have better retention than other fissure sealants. ${ }^{14}$ And an in vitro SEM analysis of surface morphology after Helioseal $F$ placement has revealed least voids, cracks and microporosities. ${ }^{15}$ Therefore, considering all the qualities, Helioseal $\mathrm{F}$ was the material of choice as a control.

Beautisealant is a fluoride releasing pit and fissure sealant that seals deep grooves and fissures while providing all round protection especially during the caries-prone years through the sustained release and recharge of fluoride and inhibits plaque accumulation. ${ }^{16}$

Conventional sealants require phosphoric acid etching which can dehydrate and demineralizes healthy tooth structure. Beautisealant self-etch primer contains dual adhesive monomers have higher $\mathrm{pH}$ that thoroughly penetrate into deep pits and fissures to prime the tooth surface for an effective chemical bond to the sealant while minimizing any damage to enamel by partially dissolving hydroxyapatite for filling it by resin. ${ }^{17}$

Clinical performance of both the sealants was evaluated using the Modified United States Public Health Service (USPHS), Ryge Criteria for Direct Clinical Evaluation of Restoration. ${ }^{18}$ The reason for opting for this criterion was its simplicity, easy to record the data in a presentable form and easy communication.

Recording of presence and absence of plaque accumulation was done to check for plaque inhibiting property of Beautisealant as no clinical study according to literature has been done for the same.

Time of application is an important consideration when all the four molars require sealant application. Increased time of application by conventional phosphoric acid etch and rinse hampers isolation and thus retention. In the selfetch approach, the etching and priming steps are combined into a single step procedure, without the need for washing. This reduces the chair side time and technique sensitivity, especially for uncooperative children. ${ }^{19}$

In our study the application time for the self-etch primer system was significantly less than that of phosphoric acid etch and rinse.

\section{Retention}

The efficacy of sealants in preventing caries has been associated with the duration and degree of sealant retention. Mechanical retention of sealants is the direct result of resin penetration into pits and fissures and porous micromechanical tags. ${ }^{20}$ Ledger et al reposted that etching of enamel surface with $37 \%$ phosphoric acid solution for 60 seconds result in $27.1 \mu \mathrm{m}$ etching depth. ${ }^{21}$

In the present study, in both the groups, there was loss of retention with time but comparison of retention in Group 1 (Helioseal F) and Group 2 (Beautisealant), retention of Helioseal $F$ was significantly more than that of Beautisealant at 3, 6 and 12 months follow up.

In a similar study, Rajashekar Reddy et al (2015) evaluated two pit and fissure sealants for 12 months, 
Helioseal F showed $53.57 \%$ complete retention, 37.50\% partial retention..$^{22}$ Güçyetmez T et al (2017), Beautisealant showed poor retention rate at 15 months follow up. Only $24.2 \%$ showed complete retention and $43.3 \%$ showed partial retention. ${ }^{23}$

Marginal Staining is an important parameter in the evaluation of the clinical success of sealant material, mainly at the sealant margin. Etching procedures might increase adhesion to enamel of sealant materials, allowing better marginal adaptation. ${ }^{24}$ The presence of a marginal gap can lead to marginal staining, which can be considered the first sign of sealant failure.

In the present study, both Group 1 (Helioseal F) and Group 2 (Beautisealant) showed marginal staining after 12 months evaluation. Only teeth containing pit and fissure sealants were recorded. Beautisealant showed slightly better response against marginal staining but the difference was not statistically significant. Ninave N et al (2012) evaluated and compared marginal staining of two fluoride releasing pit and fissure sealants. Both the materials showed similar results with respect to marginal staining and in Helioseal F, $86.7 \%$ teeth showed no marginal discoloration. ${ }^{2,5}$

\section{Development of carious lesion}

Pit and fissure sealants have shown to have better preventive property than any other tooth dentifrice education because of its better compliance. In the present study, there was no development of carious lesion in both the groups at 3 and 6 months, only 1 tooth in each group showed initial caries development at 12 month follow up. Su HR et al concluded that the clinical anticariogenic effect of one-step etching adhesives and phosphoric acid etching sealant was similar. ${ }^{25}$

Plaque accumulation: In the present study, plaque accumulation was evaluated at 3,6 and 12 months interval to check for plaque inhibition property of Beautisealant. Both the sealant showed plaque inhibition. On evaluation, only negligible number of teeth in both the groups showed plaque deposition but there was no statistically significant difference in 3, 6 and 12 months follow up.

\section{Limitations}

1. The present in-vivo study needs a long term clinical follow-up to strengthen the efficacy of pit and fissure sealants.

2. Comparison of fluoride release property of both the sealants.

3. Measurement of fluoride recharging property of Beautisealant.

4. Small sample size

\section{Conclusion}

The application of pit \& fissure sealant is highly effective in preventing caries in young population \& reduction of caries development is more related to the quality of sealant retention, instead of to the content of the material. Successful retention \& cost effectiveness of Helioseal $\mathrm{F}$ is more critical than the self-etching primer system, just to eliminate the phosphoric acid etching for ease of treatment \& saving time.

\section{Source of funding}

None.

\section{Conflict of interest}

None.

\section{References}

1. Heymann H, Swift EJ, Ritter AV, Sturdevant C. Sturdevant's. Art and Science of Operative Dentistry. Ed 6. St. Louis, Mo: Elsevier/Mosby; 2013.

2. Hesse D, Bonifácio C, Mendes F, Braga M, Imparato J, Raggio D. Sealing versus partial caries removal in primary molars: a randomized clinical trial. BMC Oral Health 2014;14:58.

3. Yazici AR, Karaman E, Baseren M, Tuncer D, Yazici E, Unluer S. Clinical evaluation of a nanofilled fissure sealant placed with different adhesive systems: 24-month results. Oper Dent 2009;34(6):642-7.

4. Feigal, RJ, Donly K.J. The Use of Pit and Fissure Sealants. Pediatr Dent 2006;28(2):143-50.

5. Maher M., Elkashlan HI., El-Housseiny AA. Effectiveness of a self-etching adhesive on sealant retention in primary teeth. $J$ Pediatr Dent 2013;35(4):351-4.

6. http://stattrek.com/statistics/random-number-generator.aspx

7. Barnes DM, Blank LW, Gingell JC, Gilner PP. A clinical evaluation of a resin-modified glass ionomer restorative material. JADA 1995;126:1245-53.

8. Mittal M, Chaudhary P, Chopra R, Khattar V. Oral health status of 5 years and 12 years old school going children in rural Gurgaon, India: An epidemiological study. J Indian Soc Pedod Prev Dent 2014;32:3-8.

9. Dhar V, Bhatnagar M. Dental caries and treatment needs of children (6-10 years) in rural Udaipur, Rajasthan. Indian J Dent Res 2009;20:256-60.

10. Wendt LK, Koch G, Birkhed D. On the retention and effectiveness of fissures sealants in permanent molars after 1520 years: A cohort study. Community Dent Oral Epidemiol 2001;29:302-7.

11. Karunakaran R, Somasundaram S, Gawthaman M, Vinodh S, Manikandan S, Gokulnathan S. Prevalence of dental caries among school-going children in Namakkal district: A crosssectional study. J Pharm Bioallied Sci 2014;6:S160-1.

12. Scheller-Sheridan C. John Wiley \& Sons. Basic Guide to Dental Materials. Pp: 74-78. ISBN 978-1-118-70831-6.

13. Reichl FX., Esters M, Simon S, Seiss M, Kehe K, Kleinsasser N. Cell death effects of resin-based dental material compounds and mercurials in human gingival fibroblasts. Arch Toxicol 2006;80:370-7.

14. Ninawe N, Ullal NA, Khandelwal V. A 1-year clinical evaluation of fissure sealants on permanent first molars. $J$ Contemp Clin Dent 2012;3(1):54-9.

15. Markovic D, Petrovic B, Peric T. Fluoride content and recharge ability of five glassionomer dental materials. BMC Oral Health 2008;8:21.

16. Dionysopoulo D, Sfeikos T, Tolidis K. Fluoride release and recharging ability of new dental sealants. Eur Arch Paediatr Dent 2016;17(1):45-51.

17. Van Meerbeek B, Yoshihara K, Yoshida Y, Mine A, De Munck J, Van Landuyt K.L. State of the art of self-etch adhesives. Dent Mater J 2011;27:17-28.

18. Barnes DM, Blank LW, Gingell JC, Gilner PP. A clinical evaluation of a resin-modified glass ionomer restorative material. JADA 1995;126:1245-53. 
19. Perdigao J, Geraldeli S, Hodges JS. Total-etch versus self-etch adhesive: effect on postoperative sensitivity. J Am Dent Assoc 2003; 134:1621-9.

20. Garcia-Godoy F, Gwinnett AJ. An SEM study of fissure surfaces conditioned by scrapping technique. Clin Prev Dent 1987;9:9-13.

21. Legler LR, Retief DH, Bradley EL Effects of phosphoric acid concentration and etch duration on the enamel depth etch: an in vitro study. Am J Orthod Dentofacial Orthop 1990;98:154-60.

22. Reddy V, Chowdhary N, Mukunda K, Kiran N, Kavyarani B, Pradeep M. Retention of resin-based filled and unfilled pit and fissure sealants: A comparative clinical study. Contemp Clin Dent 2015;6(1 suppl):18S-23S

23. Topal BG, Kirzioglu Z, Koskan O. Comparison of Different Fissure Sealants Applied to Erupting First Permanent Molar Teeth in Terms of Retention. Turkiye Klinikleri. Dishekimligi Bilimleri Dergisi 2017;23(1):24-32.
24. Perry AO, Rueggeberg F. The effect of acid primer or conventional acid etching on microleakage in a photoactivated sealant. Pediatr Dent 2003;25:127-31.

25. Su HR, Xu PC, Qian WH. Evaluation of the effect of one-step self-etching adhesives applied in pit and fissure sealing. Shanghai Kou Qiang Yi Xue 2016;25(3):317-21.

How to cite the article: Sharma S, Chopra R, Jhingan P, Sachdev $\mathrm{V}$. A randomized split mouth study for comparison of clinical success rate of GIOMER based sealant and conventional fluoride releasing pit and fissure sealant in first permanent molars: $J$ Dent Specialities 2019;7(2):78-83. 